\title{
Does contralateral knee range of motion predict postoperative knee range of motion after total knee arthroplasty?
}

\author{
Robert R. Burnham Jrr*, Samantha E. Bialek², Amy Wozniak ${ }^{3}$ and Nicholas M. Brown ${ }^{1}$
}

\begin{abstract}
Purpose: The aim of this study was to determine if contralateral knee range of motion is associated with postoperative range of motion in the operative knee after total knee arthroplasty.

Methods: Contralateral (nonoperative) knee range of motion was compared to postoperative knee range of motion after total knee arthroplasty using linear regression models in 59 patients who had undergone primary total knee arthroplasty with a minimum of 4 months postoperative follow-up data (range 4-13 months).

Results: A strong linear relationship was observed between contralateral knee ranges of motion of $115^{\circ}$ or greater and postoperative knee ranges of motion after total knee arthroplasty (slope $0.93,95 \% \mathrm{Cl} 0.58-1.29, P<0.0001$ ), with a mean difference of $-7.44^{\circ}(95 \% \mathrm{Cl}-10.3$ to $-4.63, P<0.0001)$. However, there was no association between contralateral knee range of motion and postoperative knee range of motion when contralateral knee range of motion was less than $115^{\circ}$.

Conclusion: Contralateral knee range of motion of $115^{\circ}$ or greater correlates linearly with postoperative range of motion after total knee arthroplasty, and thus may be predictive in such cases.
\end{abstract}

Keywords: Total knee arthroplasty, Contralateral range of motion, Postoperative range of motion

\section{Introduction}

An important goal of total knee arthroplasty (TKA) is to achieve satisfactory postoperative range of motion (ROM) for the patient, as ROM is an important outcome measure of TKA [1-4] and is the main component of most knee scoring systems $[5,6]$. Several studies have sought to determine predictive factors of postoperative ROM after TKA, and this is an area of active research $[4,7-9]$.

Of note, Ritter et al. [1] retrospectively studied 3066 patients (4727 knees) with primary TKA using statistical clustering, log-linear regression and regression tree analysis, and found the strongest predictor of postoperative

\footnotetext{
* Correspondence: Robert.Burnham@lumc.edu

'Department of Orthopaedic Surgery \& Rehabilitation, Loyola University Medical Center, 2160 S. First Avenue, Maguire Suite 1700, Maywood, IL 60153, USA

Full list of author information is available at the end of the article
}

ROM after TKA by far to be preoperative ROM, regardless of preoperative alignment. While some statistically significant relationships were found with reduced postoperative flexion and other factors such as female sex, intraoperative flexion and preoperative tibiofemoral alignment, they concluded these statistical relationships bore little to no clinical significance. Anouchi et al. [3] also included these factors in addition to previous surgery and modification of posterior femoral condyle geometry in their analyses through a multicenter prospective study with 621 patients and found only preoperative ROM and scores to be predictive of post-TKA ROM. The predictive value of posterior cruciate ligament status for post-TKA ROM has also been debated in the literature but has also not been shown to be a predictive factor [10]. Similarly, implant design and insert type have not been shown to affect postoperative ROM

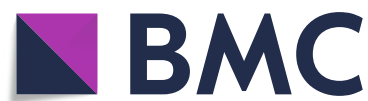

Part of Springer Nature (c) The Author(s). 2020 Open Access This article is licensed under a Creative Commons Attribution 4.0 International License, which permits use, sharing, adaptation, distribution and reproduction in any medium or format, as long as you give appropriate credit to the original author(s) and the source, provide a link to the Creative Commons licence, and indicate if changes were made. The images or other third party material in this article are included in the article's Creative Commons licence, unless indicated otherwise in a credit line to the material. If material is not included in the article's Creative Commons licence and your intended use is not permitted by statutory regulation or exceeds the permitted use, you will need to obtain permission directly from the copyright holder. To view a copy of this licence, visit http://creativecommons.org/licenses/by/4.0/. The Creative Commons Public Domain Dedication waiver (http://creativecommons.org/publicdomain/zero/1.0/) applies to the data made available in this article, unless otherwise stated in a credit line to the data. 
[11-16]. Several other studies have evaluated a variety of demographic and comorbidity-related factors that have shown to have some but variable predictive value $[4,8$, $9,17,18]$.

To date, the factor that has consistently been shown in the literature and is well established to predict postoperative $\mathrm{ROM}$ is preoperative $\mathrm{ROM}$ in the same knee $[4,8$, 9, 19-21]. Preoperative flexion has consistently been shown to be the strongest predictor of postoperative flexion $[1,2,4,10,12,22]$. Other studies on post-TKA outcomes have expanded to include the contralateral, nonoperative knee in analyses. Such studies have evaluated contralateral knee osteoarthritis, pain and biomechanics to predict the need for contralateral TKA after primary TKA $[23,24]$. At our institution, we have observed post-TKA outcomes in the operative knee such as ROM, flexion contracture and need for manipulation under anesthesia (MUA) which appear to eventually match that of the preoperative contralateral, nonoperative knee in our patients. Patients with better baseline contralateral knee ROM tend to achieve similar postTKA ROM in the operative knee, and those with less baseline ROM in the contralateral knee tend to have worse post-TKA ROM. These observations have thus led us to hypothesize that contralateral knee ROM may be predictive for postoperative knee ROM after TKA.

While studies on post-TKA outcomes and predictors have begun to include various evaluations of the contralateral knee [23-26], to our knowledge there are no studies in the literature to date on whether ROM in the contralateral, nonoperative knee is predictive of postoperative ROM in the operative knee after TKA. Thus, the purpose of the present study was to determine if postoperative knee ROM after TKA can be predicted by a patient's preoperative $\mathrm{ROM}$ in the nonoperative knee by comparing postoperative ROM arc measurements after TKA to preoperative ROM arc measurements in the nonoperative knee.

\section{Methods}

Patients

Following Institutional Review Board approval, all patients who had undergone a primary TKA performed by one surgeon at our institution between September 2017 and June 2019 were initially considered for inclusion in this retrospective study $(n=84)$. Because 12 of those patients underwent staged bilateral TKAs performed within 2 to 13 months of each other, only postoperative data from the second surgery was included in statistical analyses $(n=72)$ and the postoperative data from the first surgery was excluded $(n=12)$. Of the 72 patients, only those with a minimum of 4 months postoperative follow-up data (range from 4-13 months) were included in statistical analyses for ROM $(n=59)$. ROM measurements of bilateral knees, including flexion, extension and ROM arc, were recorded pre- and postoperatively. Analyses for outcomes of flexion and manipulation had varying sample sizes depending on missing data. The presence or absence of a flexion contracture, the need for postoperative MUA, implant type, age, sex and type of preoperative osteoarthritis (varus, valgus, neutral) were also recorded and included in statistical analyses. Preoperative ROM in the contralateral, nonoperative knee was compared to postoperative ROM arc in the operative knee.

\section{Statistical methods}

Scatter plots and LOESS curves were used to evaluate the linear relationship between contralateral knee ROM and postoperative ROM in the operative knee at final followup. The results illustrated a piecewise linear relationship with a knot at $115^{\circ}$. Thus, regression models with a spline were used to evaluate the association of contralateral knee $\mathrm{ROM}$ and postoperative ROM for the operative knee at final follow-up below contralateral ROM of $115^{\circ}$ and above contralateral ROM of $115^{\circ}$ (Fig. 1). Differences between a priori risk factors were assessed using interaction terms of slope prior to $\mathrm{ROM}$ of $115^{\circ}$ and greater than $115^{\circ}$. Fisher exact tests were used to test the association of contralateral knee flexion contracture with postoperative knee flexion contracture at final follow-up and MUA, and Fisher exact tests were used to test the association for contralateral ROM and MUA.

\section{Results}

The average age of the patient population studied was 62.8 years (standard deviation $=9.4$ ), $58 \%$ of which were female and $42 \%$ male. Overall, $75 \%$ of patients had preoperative varus osteoarthritis and $82 \%$ of patients had a posterior-stabilized (PS) implant (Table 1).

At a contralateral $\mathrm{ROM}$ of $115^{\circ}$ or greater there was a strong linear relationship observed between contralateral ROM and postoperative ROM (slope 0.93, 95\% confidence interval (CI) 0.58-1.29; $P<0.0001$; Table 2). For every unit increase in a contralateral knee ROM of $115^{\circ}$ or greater, there was a $0.93^{\circ}$ increase in postoperative ROM in the operative knee. On average, for values greater than $115^{\circ}$, the difference in postoperative knee ROM tended to be -7.44 (95\% CI -10.3 to $-4.63 ; P<$ 0.0001) compared to contralateral knee ROM (Table 3) (Fig. 1). However, there was no association when the contralateral ROM was less than $115^{\circ}$. Results were similar for all subgroups and there were no differences between subgroups for any of the other predictors studied (Tables 2 and 3).

Six of nine (66\%) patients with a contralateral knee flexion contracture lacked full extension on their operative knee compared to 13 of 49 (26\%) without a contralateral flexion contracture $(P=0.0496)$. 


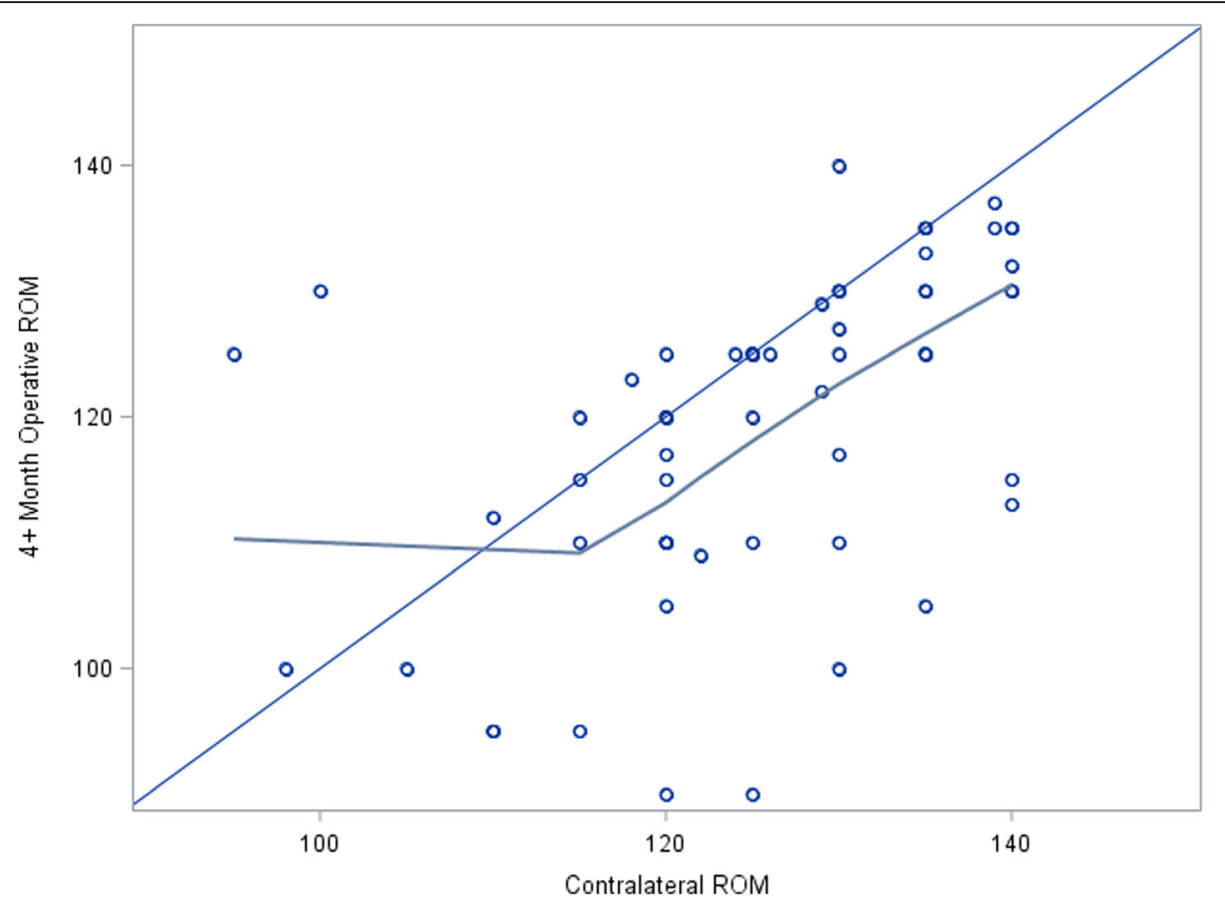

Fig. 1 Regression model with spline. Relationship between post-total knee arthroplasty (TKA) range of motion (ROM) at final follow-up and contralateral ROM of $<115^{\circ}$ and $\geq 115^{\circ}$. Dark blue line: LOESS curve illustration of relationship between contralateral ROM and post-TKA ROM at final follow-up. Light blue line: reference line where contralateral ROM is perfectly predictive of post-TKA ROM at final follow-up

There were only five patients in this cohort who, due to significant postoperative stiffness, were indicated for postoperative MUA after their TKA, which made comparisons difficult. Among these five patients, MUA was performed at a mean of 9 weeks post-TKA. However, contralateral ROM was not associated with the need to perform postoperative MUA (0/9 (0\%) ROM $<115^{\circ}$ versus 5/63 (7.94\%) $\left.\mathrm{ROM} \geq 115^{\circ} ; P=1.000\right)$, nor was contralateral flexion contracture $(1 / 9$ (11\%) flexion contracture versus $4 / 61$ (7\%) no flexion contracture; $P=0.509$ ).

\section{Discussion}

These results suggest that when the nonoperative, contralateral knee ROM is $115^{\circ}$ or greater it may be used as a predictor for postoperative ROM after TKA.

Table 1 Patient characteristics, $n=72$

\begin{tabular}{ll}
\hline Patient characteristic & $\boldsymbol{n}(\%)$ or mean (SD) \\
\hline Male & $30(42)$ \\
Female & $42(58)$ \\
Age (years) & $62.8(9.4)$ \\
Varus & $54(75)$ \\
Valgus & $7(10)$ \\
Neutral & $11(15)$ \\
CR & $13(18)$ \\
PS & $59(82)$ \\
\hline
\end{tabular}

$C R$ cruciate retaining, $P S$ posterior stabilized, SD standard deviation
Additionally, the presence of a contralateral knee flexion contracture may predict postoperative flexion contracture in the operative knee after TKA. Patients mobilize in a relatively symmetric manner; thus, the contralateral knee influences the motion of the operative knee after TKA. As patients begin to walk, climb stairs, squat and sit with increased frequency postoperatively, as most do by final follow-up post-TKA, the contralateral knee continues to influence the ultimate motion of the operative knee. Excellent motion in one knee promotes excellent motion in the other knee, consistent with the threshold value of $115^{\circ}$ suggested by our results.

At contralateral knee ROM less than $115^{\circ} \mathrm{ROM}$ is less optimal and its influence on ROM of the operative knee is more variable. While contralateral knee ROM less than $115^{\circ}$ did not linearly correlate with post-TKA ROM, it is important to note contralateral ROM less than $115^{\circ}$ did not limit the operative knee in achieving a functional ROM; all patients in this cohort achieved a functional ROM after TKA. While interpretation of these results and the proposed threshold value of contralateral knee ROM must take our sample size into consideration, the present study does offer the first attempt at predicting postoperative ROM after TKA according to preoperative contralateral knee ROM; a strong association at or above contralateral knee ROM of $115^{\circ}$ was observed in this patient cohort. 
Table 2 Outcome: postoperative ROM at final follow-up for operative knee; predictor: contralateral $\mathrm{ROM}, n=59$

\begin{tabular}{|c|c|c|c|c|c|}
\hline Predictor & $\begin{array}{l}\text { Association prior to } 115^{\circ} \text {, } \\
\text { slope }(95 \% \mathrm{Cl})\end{array}$ & $\begin{array}{l}P \\
\text { value }\end{array}$ & $\begin{array}{l}\text { Association from } 115^{\circ} \text {, } \\
\text { slope }(95 \% \mathrm{Cl})\end{array}$ & $\boldsymbol{P}$ value & $\begin{array}{l}\text { Difference between } \\
\text { groups, } \\
\boldsymbol{P} \text { value }\end{array}$ \\
\hline Contralateral ROM, all patients & $-0.32(-1.1,0.43)$ & 0.4016 & $0.93(0.58,1.29)$ & $<0.001$ & NA \\
\hline Contralateral ROM, male & $0.47(-0.88,1.83)$ & 0.4841 & $0.99(0.48,1.51)$ & 0.0003 & 0.7664 \\
\hline Contralateral ROM, female & $-0.61(-1.55,0.32)$ & 0.1951 & $0.89(0.37,1.40)$ & 0.0010 & \\
\hline Contralateral ROM, age <63 & $-0.84(-2.16,0.49)$ & 0.2088 & $1.14(0.66,1.61)$ & $<0.0001$ & 0.2158 \\
\hline Contralateral ROM, age $\geq 63$ & $0.03(-0.91,0.97)$ & 0.9481 & $0.68(0.10,1.25)$ & 0.0216 & \\
\hline Contralateral ROM, varus & $-0.90(-1.78,-0.02)$ & 0.0445 & $0.84(0.44,1.24)$ & 0.001 & 0.9119 \\
\hline Contralateral ROM, valgus & NE & & $0.92(-0.41,2.25)$ & 0.1723 & \\
\hline Contralateral ROM, neutral & NE & & $\mathrm{NE}$ & & \\
\hline Contralateral ROM, CR & NE & & $1.344(0.49,2.19)$ & 0.0025 & 0.2924 \\
\hline Contralateral ROM, PS & $-0.23(-1.01,0.55)$ & 0.5569 & $0.85(0.44,1.25)$ & $<0.0001$ & \\
\hline
\end{tabular}

$\mathrm{Cl}$ confidence interval, $C R$ cruciate retaining, $N A$, not applicable, $N E$ not estimated (due to small sample size), $P S$ posterior stabilized, $R O M$ range of motion

As mentioned, preoperative ROM in the operative knee is well established as the best predictor of postoperative ROM after TKA [1, 2, 4, 8-10, 12, 19-22, 27]. In two recently developed clinical predictive models by Pua et al. [9] and Stratford et al. [7], preoperative ROM and scores are primarily used to predict postoperative knee measures, with little if any weight in their models placed on other statistically significant factors such as patient sex, age, body mass index, underlying disease, preoperative walking limitations and pain.

The literature on preoperative risk factors and predictors for post-TKA flexion contracture and need for MUA mirrors that of predictors for post-TKA ROM, with the strongest and most reliable predictor being the presence of a preoperative flexion contracture in the operative knee, not readily varied by other factors $[1,2,9$, $16,19,21,28,29]$. Harato et al. [25, 26] have conducted gait and weight bearing studies in patients with flexion contractures and have delineated the abnormal forces placed on the contralateral knee in TK A[26] and nonTKA settings [25]. They have demonstrated that flexion contractures $>15^{\circ}$ after TKA promotes progression of osteoarthritis and the need for TKA in the contralateral knee but have not studied such an association with contralateral knee flexion contracture [30], as have no other studies in the literature to date. Our results suggest a possible association between the presence of any degree of contralateral knee flexion contracture and flexion contracture after TKA in the operative knee. Contralateral flexion contracture may thus serve as a predictive factor for post-TKA flexion contracture.

This study included PS versus cruciate retaining (CR) implants as a subgroup in our statistical analyses and we found similar results for all subgroups and no differences between subgroups, including PS versus CR $(P=0.6412)$. These results support those of the several studies

Table 3 Difference in contralateral and postoperative ROM where contralateral $\mathrm{ROM} \geq 115, n=52$

\begin{tabular}{|c|c|c|c|c|c|}
\hline Predictor & $n$ & $\begin{array}{l}\text { Mean (SD) ROM of } \\
\text { Operative Knee }\end{array}$ & $\begin{array}{l}\text { Mean (SD) ROM of } \\
\text { Contralateral Knee }\end{array}$ & $\begin{array}{l}\text { Difference } \\
\text { (95\% Cl) }\end{array}$ & $\begin{array}{l}\text { Difference between } \\
\text { groups, } \\
\boldsymbol{P} \text { value }\end{array}$ \\
\hline Contralateral ROM, all patients & 52 & $120.8(12.1)$ & $128.3(8.0)$ & $-7.44(-10.3,-4.63)^{*}$ & NA \\
\hline Contralateral ROM, male & 22 & $121.6(13.0)$ & $128.6(9.1)$ & $-7.00(-11.2,-2.8)^{*}$ & 0.7857 \\
\hline Contralateral ROM, female & 30 & $120.3(11.5)$ & $128.0(7.2)$ & $-7.77(-11.8,-3.7)^{*}$ & \\
\hline Contralateral ROM, age $<63^{\mathrm{a}}$ & 26 & $120.8(12.6)$ & $129.0(8.9)$ & $-8.2(-11.65,-4.7)^{*}$ & 0.5981 \\
\hline Contralateral $\mathrm{ROM}$, age $\geq 63^{\mathrm{a}}$ & 26 & $120.9(11.7)$ & $127.6(7.1)$ & $-6.7(-11.3,-2.0)^{*}$ & \\
\hline Contralateral ROM, varus & 39 & $118.9(12.1)$ & $127.1(8.1)$ & $-8.3(-11.4,-5.1)^{*}$ & 0.3408 \\
\hline Contralateral ROM, valgus & 6 & $127.8(8.1)$ & $127.5(6.9)$ & $0.3(-12.6,12.23)$ & \\
\hline Contralateral ROM, neutral & 7 & $125.9(12.6)$ & $135.4(4.5)$ & $-9.6(-20.9,1.77)$ & \\
\hline Contralateral ROM, CR & 10 & $120.6(14.1)$ & $129.1(8.4)$ & $-8.5(-14.9,-2.1)^{*}$ & 0.6412 \\
\hline Contralateral ROM, PS & 42 & $120.9(11.7)$ & $128.1(8.0)$ & $-7.2(-10.4,-3.9)^{*}$ & \\
\hline
\end{tabular}

Cl confidence interval, $C R$ cruciate retaining, $N A$, not applicable, $P S$ posterior stabilized, $R O M$ range of motion, $S D$ standard deviation

${ }^{a}$ Dichotomized at median age

*Significantly different from $0(P<0.05)$ 
(randomized controls [11], retrospective [15] and prospective [16] analyses and meta-analyses [12-14]) that have previously demonstrated implant type to have no significant effect on postoperative ROM after TKA, both statistically $[11,13,15,16]$ and clinically [11-16]. As an example, the meta-analysis of Bercik et al. [12] comparing PS versus CR in TKA concluded that while there may be a statistically significant difference in postoperative ROM favoring PS implants, the clinical importance of this is unknown and therefore the decision to use PS versus $C R$ implants should still be based on surgeon preference and comfort. Other studies have more definitively demonstrated no difference between PS and $\mathrm{CR}$ on post-TKA ROM and have concluded that implant type lacks predictive value for post-TKA ROM $[11,13-16]$.

Limitations of the present study include its sample size and relatively short follow-up time. This must be considered when interpreting our results. Additionally, while there is a relatively high rate of patients that lacked full extension in this cohort, for many of these patients this is likely due to a relatively short postoperative follow-up time (between 4 months to 1 year); the lack of full extension in these patients was around $3-5^{\circ}$. Finally, there was a relatively high rate of MUA. The surgeon in this study has a historical rate of MUA of around 3\%. It is possible that this higher rate was due either to a closer emphasis on measuring ROM in these patients, or to a statistical abnormality given our smaller sample size.

While the study is limited by sample size, given that data were used only from TKAs performed by one surgeon, a major strength is its elimination of inter-surgeon variability. The authors view this as somewhat of a trade-off for the smaller sample size. Another strength is the study's novelty-this hypothesis has not been tested before in the literature to date. The study offers a first attempt at using contralateral knee ROM to predict postoperative ROM after TKA that may be confirmed in future studies with larger sample sizes and longer postoperative follow-up.

Since the predictive value of many patient factors that have been studied to date for postoperative ROM after TKA remains low $[3,7,8,10-16]$ or variable $[9,17]$, preoperative $\mathrm{ROM}$ in the operative knee is most often used to predict postoperative ROM after TKA [4, 8-10, $22]$. There remains a paucity of other reliable, clinically relevant and practical predictive factors. Thus, despite its limitations, the results of the present study may offer another strong clinical predictor to consider contralateral knee ROM when it is $115^{\circ}$ or greater.

\section{Conclusion}

Our results suggest that contralateral knee ROM has a strong positive association with postoperative ROM after
TKA when contralateral knee $\mathrm{ROM}$ is $115^{\circ}$ or greater. Additionally, our results suggest flexion contracture in the contralateral knee is predictive of postoperative flexion contracture in the operative knee after TKA. These results may thus serve as a predictor for postoperative ROM after TKA and may perhaps also be referenced in preoperative discussions with patients regarding anticipated post-TKA outcomes.

\section{Acknowledgements \\ Not applicable.}

\section{Authors' contributions}

RRB and SEB acquired and interpreted the data and were major contributors in writing the manuscript. AW statistically analyzed and interpreted the data and was a major contributor in writing the manuscript. NMB conceived and designed the study, interpreted the data, and was a major contributor in writing the manuscript. All authors read and approved the final manuscript.

Funding

No funds were received in support of this study.

\section{Availability of data and materials}

The datasets generated and/or analyzed during the current study are available from the corresponding author on reasonable request.

\section{Ethics approval and consent to participate}

This study has been approved by the Institutional Review Board of our institution and assigned a status of "exempt", reference number 212744.

Consent for publication

Not applicable.

\section{Competing interests}

The authors declare that they have no competing interests.

\section{Author details}

'Department of Orthopaedic Surgery \& Rehabilitation, Loyola University Medical Center, 2160 S. First Avenue, Maguire Suite 1700, Maywood, IL 60153, USA. ${ }^{2}$ Stritch School of Medicine, Loyola University Chicago, 2160 S. First Avenue, Maywood, IL 60153, USA. ${ }^{3}$ Center for Translational Research, Loyola University Chicago, 2160 S. First Avenue, Maywood, IL 60153, USA.

Received: 11 February 2020 Accepted: 11 May 2020

Published online: 05 June 2020

\section{References}

1. Ritter MA, Harty LD, Davis KE, Meding JB, Berend ME (2003) Predicting range of motion after total knee arthroplasty: clustering, log-linear regression, and regression tree analysis. J Bone Joint Surg Am 85(7):1278-1285

2. Schurman DJ, Matityahu A, Goodman SB, Maloney W, Woolson S, Shi H et al (1998) Prediction of postoperative knee flexion in Insall-Burstein II total knee arthroplasty. Clin Orthop 353:175-184

3. Anouchi YS, McShane M, Kelly F Jr, Elting J, Stiehl J (1996) Range of motion in total knee replacement. Clin Orthop Relat Res 331:87-92

4. Bade MJ, Kittelson JM, Kohrt WM, Stevens-Lapsley JE (2014) Predicting functional performance and range of motion outcomes after total knee arthroplasty. Am J Phys Med Rehabil 93(7):579-585

5. Alicea J (2002) Knee scores in total knee arthroplasty. In: Scuderi GR, Tria AJ (eds) Surgical techniques in total knee arthroplasty. Springer, New York, pp 31-38

6. Kon E, Altadonna G, Filardo G, Matteo BD, Marcacci M (2014) Knee scoring systems. In: Bentley G (ed) European surgical orthopaedics and traumatology. Springer, Berlin, Heidelberg, pp 3371-3388

7. Stratford PW, Kennedy DM, Robarts SF (2010) Modelling knee range of motion post arthroplasty: clinical applications. Physiother Can 62(4):378-387

8. Rissman CM, Keeney BJ, Ercolano EM, Koenig KM (2016) Predictors of facility discharge, range of motion, and patient-reported physical function 
improvement after primary total knee arthroplasty: a prospective cohort analysis. J Arthroplast 31(12):2660-2667

9. Pua YH, Poon CL, Seah FJ, Thumboo J, Clark RA, Tan MH et al (2019) Predicting individual knee range of motion, knee pain, and walking limitation outcomes following total knee arthroplasty. Acta Orthop 90(2):179-186

10. Kotani A, Yonekura A, Bourne RB (2005) Factors influencing range of motion after contemporary total knee arthroplasty. J Arthroplast 20(7):850-856

11. Beaupre LA, Sharifi B, Johnston DWC (2017) A randomized clinical trial comparing posterior cruciate-stabilizing vs posterior cruciate-retaining prostheses in primary total knee arthroplasty: 10-year follow-up. J Arthroplast 32(3):818-823

12. Bercik MJ, Joshi A, Parvizi J (2013) Posterior cruciate-retaining versus posterior-stabilized total knee arthroplasty: a meta-analysis. J Arthroplast 28(3):439-444

13. Li N, Tan Y, Deng Y, Chen L (2014) Posterior cruciate-retaining versus posterior stabilized total knee arthroplasty: a meta-analysis of randomized controlled trials. Knee Surg Sports Traumatol Arthrosc 22(3):556-564

14. Luo SX, Zhao JM, Su W, Li X, Dong G (2012) Posterior cruciate substituting versus posterior cruciate retaining total knee arthroplasty prostheses: a meta-analysis. Knee 19(4):246-252

15. Malik A, Salas A, Ben Ari J, Ma Y, González Della Valle A (2010) Range of motion and function are similar in patients undergoing TKA with posterior stabilised and high-flexion inserts. Int Orthop 34(7):965-972

16. Kim YH, Sohn KS, Kim JS (2005) Range of motion of standard and highflexion posterior stabilized total knee prostheses: a prospective, randomized study. J Bone Joint Surg Am 87(7):1470-1475

17. Sugitani K, Arai Y, Takamiya H, Terauchi R, Nakagawa S, Ueshima K (2015) Factors affecting range of motion after total knee arthroplasty in patients with more than 120 degrees of preoperative flexion angle. Int Orthop 39(8): $1535-1540$

18. Harvey IA, Barry K, Kirby SP, Johnson R, Elloy MA (1993) Factors affecting the range of movement of total knee arthroplasty. J Bone Joint Surg (Br) 75(6): 950-955

19. Tibbo ME, Limberg AK, Salib CG, Ahmed AT, van Wijnen AJ, Berry DJ et al (2019) Acquired idiopathic stiffness after total knee arthroplasty: a systematic review and meta-analysis. J Bone Joint Surg Am 101(14): $1320-1330$

20. Li Z, Lan F, Shen Y, An S, Xu N, Yin C et al (2019) Prediction of the need for manipulation under anesthesia for flexion contracture after total knee arthroplasty in patients of advanced age. J Int Med Res 47(7):3061-3069

21. Ritter MA, Lutgring JD, Davis KE, Berend ME, Pierson JL, Meneghini RM (2007) The role of flexion contracture on outcomes in primary total knee arthroplasty. J Arthroplast 22(8):1092-1096

22. Kawamura H, Bourne RB (2001) Factors affecting range of flexion after total knee arthroplasty. J Orthop Sci 6(3):248-252

23. Zeni J Jr, Snyder-Mackler L (2016) Baseline differences between individuals who did and did not have contralateral symptomatic OA progression after TKA. Osteoarthr Cartil 24:S103

24. Aljehani M, Madara K, Snyder-Mackler L, Christiansen C, Zeni J Jr (2019) The contralateral knee may not be a valid control for biomechanical outcomes after unilateral total knee arthroplasty. Gait Posture 70:179-184

25. Harato K, Nagura T, Matsumoto H, Otani T, Toyama Y, Suda Y (2008) Knee flexion contracture will lead to mechanical overload in both limbs: a simulation study using gait analysis. Knee 15(6):467-472

26. Harato K, Nagura T, Matsumoto H, Otani T, Toyama Y, Suda Y (2010) Extension limitation in standing affects weight-bearing asymmetry after unilateral total knee arthroplasty. J Arthroplast 25(2):225-229

27. Ishii Y, Noguchi H, Takeda M, Sato J, Toyabe S (2013) Posterior condylar offset does not correlate with knee flexion after TKA. Clin Orthop Relat Res 471(9):2995-3001

28. Goudie ST, Deakin AH, Ahmad A, Maheshwari R, Picard F (2011) Flexion contracture following primary total knee arthroplasty: risk factors and outcomes. Orthopedics 34(12):e855-e859

29. Anania A, Abdel MP, Lee YY, Lyman S, González Della Valle A (2013) The natural history of a newly developed flexion contracture following primary total knee arthroplasty. Int Orthop 37(10):1917-1923

30. Onodera T, Majima T, Nishiike O, Kasahara Y, Takahashi D (2013) Posterior femoral condylar offset after total knee replacement in the risk of knee flexion contracture. J Arthroplast 28(7):1112-1116

\section{Publisher's Note}

Springer Nature remains neutral with regard to jurisdictional claims in published maps and institutional affiliations.

\section{Ready to submit your research? Choose BMC and benefit from:}

- fast, convenient online submission

- thorough peer review by experienced researchers in your field

- rapid publication on acceptance

- support for research data, including large and complex data types

- gold Open Access which fosters wider collaboration and increased citations

- maximum visibility for your research: over $100 \mathrm{M}$ website views per year

At BMC, research is always in progress.

Learn more biomedcentral.com/submissions 